\title{
Market Change and Policy Perfection in China
}

\author{
Zou Lixing ${ }^{1,2,3}$ \\ ${ }^{1}$ China Association for Social and Economic System Analysis Research, Beijing, P. R. China \\ ${ }^{2}$ Research Institute, China Development Bank, Beijing, P. R. China \\ ${ }^{3}$ China Center for Modernization Institute of Chinese Academy of Science, Beijing, P. R. China
}

\section{Email address:}

zlixing@outlook.com

\section{To cite this article:}

Zou Lixing. Market Change and Policy Perfection in China. International Journal of Economics, Finance and Management Sciences. Vol. 6, No. 5, 2018, pp. 235-245. doi: 10.11648/j.ijefm.20180605.15

Received: July 3, 2018; Accepted: October 26, 2018; Published: November 19, 2018

\begin{abstract}
This study adopt balanced way of thinking to analyze the changes in market conditions in the new era, particularly the changes in Chinese monetary conditions, financial conditions and credit condition as well as the perfection of policies. In response to the new circumstances and changes in market credit conditions, it is necessary to, from the ideological perspective, gain new understanding of the financial market to reflect our determined ideology, from the strategic perspective, to define and refine the tasks and objectives of financial system reform to reflect our strategic planning, and from the perspective of policy and technical methodology, to improve and diversify operating kits to take the initiative and enhance risk control ability. Some measurements improving and enriching policy and technical tool kits should be addressed in current economic works and in midand long development. China may have to define the tasks and goals of deepened financial structure reform, establish and perfect long-effective management mechanism, and create multi-dimensional and diverse financial ecology. To prevent asset bubbles, money supply control alone is not enough. It's advised to regulate the stock and incremental capital through securitization, such as promoting stock asset-backed securitization to further revitalize the stock of assets of financial institutions in short team, and perfect the modern credit system in long team.
\end{abstract}

Keywords: Market Condition, Financial Reform, Credit Economy, Long-Term Cycle

\section{Introduction}

The interaction between people and society is based on credit [1]. Credit is the internal cause of development, credit can be built, and credit construction can be promoted [2]. China's current market credit system is still relatively backward [3], which is a fundamental problem that restricts the country's medium and long-term sustainable development. In order to speed up the construction of the market credit system, it is necessary to profoundly understand the nature and characteristics of credit, and to reveal and grasp the basic laws of credit activities. This study will make analysis on monetary conditions, financial conditions and credit conditions respectively.

\section{Change in Monetary Conditions and Policies}

Monetary condition refers to the preconditions that something is deemed as currency. In this paper, it refers to the preconditions for the conversion of money to capital. An object with the functions of "trade medium, unit of measurement, value storage and means of payment" is money. Money is essential for economic and social development. However, money has to create values before being converted into capital, which is also an important precondition for the development of market economy.

According to Capital (Karl Marx), "In themselves, money and commodities are no more capital than are the means of production and of subsistence. They want transforming into capital. But this transformation itself can only take place under certain circumstances that center in this, viz., that two very different kinds of commodity-possessors must come face to face and into contact; on the one hand, the owners of money, means of production, means of subsistence, who are eager to increase the sum of values they possess, by buying other 
people's labor-power; on the other hand, free laborers, the sellers of their own labor-power, and therefore the sellers of labor." [4] Marx made it clear that, the most important precondition for the conversion of money to capital is available labor force. Without labor, money is an average commodity or an IOU. Money cannot become a special commodity nor be used and converted into capital unless labors are departed from their ownership of labor and the direct producers converted into employees. Therefore, from the perspective of ownership, social division of labor is the precondition of money (Table 1). Looking back into the history of primitive accumulation, establishing the market of employable labors, or creating the preconditions for capital relationship, was a crucial revolution, particularly in the early stage of capitalism. The division of labor enables labors to own products, and surplus products allow exchanges and loans. In modern and contemporary economy, labor market has been well developed and labors are entitled to their rights to work. It is easy to convert money into capital. Nevertheless, primitive accumulation and creation are complicated, through hard working, resource abundance, or even violence, cheating and theft. "As a matter of fact, the methods of primitive accumulation are anything but idyllic."

Table 1. Change in monetary conditions and policies.

Precondition for the conversion of money into Capital

Available labor Force or Labor are departed from their ownership

Free Labor Force Producer converted into employee

Along with the development of information economy and knowledge economy, on one hand, new changes have taken place in modern social environment and social development conditions. For instance, technology used to chase capital, but now the situation is reversed; employment used to go one-way from capital to labor force, but now it goes two-way between the two. Labor is converting to human capital, technical factors impose great impact on labors, and laborers vary largely in terms of technique, efficiency and ability to create wealth. On the other, primitive accumulation of wealth is even complicated. For example, labor capital takes the form of stock, i.e. individuals, families and professional brokers take shares. It has become an important phenomenon of market economy. Human capital is available through networks, allowing laborers to look for jobs and create capital relationships throughout the world. Moreover, e-money and online payment boost financial popularization. In 2016, China Mobile paid over $\$ 12$ trillion in market transactions [5]. In this sense, it is impossible for monetary authorities to maintain market order and control the total circulation of social capital merely through traditional monetary administration tools and measures. They have to make innovations in policies and improve monetary conditions. Possible options are, for example, considering the impact of Internet finance on traditional currency and of faster circulation of Internet finance on the multiplying function of base money, in addition to traditional concerns. This study will address this issue in the following parts.

\section{Change in Financial Conditions and Policies}

Financial condition refers to the preconditions for the entitlement to valuable things. In this paper, it refers to the preconditions for the conversion of financial assets into financial capital. It reflects not only the claim for financial assets, but also the value-creating effect of financial assets. This is an important property of modern financial market development.

Financial asset is a financial claim. As long as you are entitled to claim for something valuable, you own the financial assets, which mean you can claim for assignment [6] . Along with the development of internet finance technology, financial claim are increasing. At present, financial assets include five categories: currencies, stocks, bonds, foreign exchange, and securities loan. Of them, currency brings bank deposit interests, foreign exchange has exchange rates, stock brings dividends, bond and securities loans also have interests. All the assets can be transformed into capital when conditions are matured. The matured conditions are: first, potential of appreciation of the asset; second, entitlement to claim for the assets, i.e. for the total value of the appreciated financial asset; and third, liquidity. Liquidity reflects the encashment ability of various assets as required, which determines how they are accepted in the market. This is a special precondition for transforming financial assets to financial capital. China has to consider its liquidity when analyzing a financial asset, in addition to its appreciation potential and total value. The market concerns the liquidity of financial assets. The investors would accept lower interest rate of high-liquidity investment options, given the rest conditions are the same, and vice versa. For poor-liquidity bonds, investors expect higher return to compensate the loss in liquidity (see Table 2).

Table 2. Change in financial conditions and policies.

\begin{tabular}{ll}
\hline $\begin{array}{l}\text { Precondition for the conversion of Financial asset into Financial } \\
\text { Capital }\end{array}$ \\
\hline \begin{tabular}{ll} 
Liquidity & Appropriate operation of supplier and user \\
Translation & $\begin{array}{l}\text { Appropriate action of financial intermediaries } \\
\text { Appropriate correlation between virtual and real economy }\end{array}$ \\
\hline
\end{tabular}
\end{tabular}

In current financial market, the five categories differ in encashment ability due to different difficulties in market transaction. If a sector has all its financial assets in the form of money, it boasts high asset liquidity. If a sector's all assets are hard to convert into case (e.g. long-term bonds), it suffers poor asset liquidity. In international payment, liquidity represents the ability of a country or a region to cover external payment balance, and its necessary foreign exchange reserve. In the commercial banking system, liquidity explains the ability of the bank to satisfy depositors' claim for cash, and its cash and short-term assets in possession. In the securities market, liquidity reflects the market values of marketable products. The more stocks issuance, the more market makers; the wider the stock holding, the higher the stock liquidity in market. In the monetary market, liquidity shows the total volume of 
money and short-term financial assets in economic activities. Excessively loose monetary policy makes it hard to distinguish base money from other current assets, and easy to lead to excessive liquidity. Therefore, in terms of financial administration, various countries/regions should, depending on their financial market and financial asset, develop their own macro policies, the general goals of which are economic growth, price stability, higher employment rate and trade balance. [7]

Along with the development of technology, non-liquid assets have liquidity, and all forms of assets can be used as money in settlement or as capital in investment. As the financial market develops, more and more financial derivatives come into being, financial assets have more complex structures, financial liquidity are harder to control, and more and more assets have capital properties. Therefore, it is necessary to make in-depth study on and appropriate improvements of financial conditions.

Here, it is significance to address that internet finance is not a traditional financial institution that simply uses the Internet to achieve networking and convenience. It is a new investment and financing operation platform with financial functions based on Internet technology (search engine and social network). Although Internet finance seeks to form a more flat, efficient and transparent intermediary, forming a distinctive financial environment, it is essentially a process of credit activities and a process of financial intermediation. The Internet and financial development have a natural fusion of genes. The concept of open sharing and participation of everyone on the Internet, as well as the innate advantages of realizing big data acquisition and analysis based on the Internet and mobile terminals are of great significance for realizing the financial functions that are difficult to achieve under the traditional transaction mode.

By learning from history, the smooth circulation of financial assets in financial system is decided by three preconditions. First and fundamentally, it calls for appropriate operation of the suppliers and users of financial asset. That is to say, the financial asset suppliers should provide adequate financial assets. It depends on various factors: whether enterprises could improve economic efficiency and convert more profits into retained earnings, whether governments at all levels could control the situation and maintain budgetary balance and appropriate surplus, whether individuals make proper arrangement of income and expense and have savings after meeting their demands. If they do so, it means adequate supply of financial assets and benefits low-cost, high-quality fund supply. Meanwhile, the users of financial assets should make good of the funds and maximize investment returns. It also depends on various factors: whether enterprises, for the purpose of expanding production, could choose appropriate projects that benefit industrial upgrading and new products for marketing, whether the governments could spend more money on public infrastructures that benefit the knowledge and innovation system, and whether individuals could spend money on improving their physical, mental, living and cultural qualities. If they do so, the financial assets are in necessary and effective use and the expansion of reproduction is in a sound cycle.

Second, financial intermediaries should abide by financial regulations. They are responsible to provide good services to help reasonable allocation of financial assets and maintain financial order. If they are reluctant to loan fund users, it would possibly cause financial stringency and economic downturn. However, if they keep lending when the economy is overheat, the economic situation would be worsen and lead to calamity.

Third, it calls for appropriate correlation between virtual and real economies, which are closely interlaced but vary in attributes. Virtual economy pursues high profits at the cost of high risk, with real economy as the carrier, and "by setting up credit mechanism" [8]. Real economy, by means of industrial assets, provides visible and physical products and services. If virtual economy deviates too far away from real economy, it would likely cause financial crisis. In late 2007 and 2008, the US suffered subordinated bond catastrophe, one of the major reasons for which was the ridiculously overheated financial derivatives. The history tells that, poor control over financial innovations and financial conditions are the prelude of financial crisis. To avoid the negative possibilities, it is necessary to improve financial conditions through, for example, first, raising the access bar of mortgage loans, second, keeping the price of financial derivatives below the base value, and third, requiring financial enterprises to make available credit risk reserves (no less than 5\% in the US).

China's total financial assets are worth three times GDP, or over RMB 120 trillion, and keep increasing [9]. How to make good use of the money and create more wealth and how to safeguard financial assets against the complex and ever-changing circumstance and to create appropriate values? The financial sector has to work out proper answers to the questions through, not only creating conditions to encourage financial innovation, improving the financial market, diversifying financial products, providing more investment products, but also making good control over the conditions, standardizing the market, enhancing the regulatory system and mastering the laws and characteristics of financial assets. For example, it is necessary to, according to the new trends of liquidity, monitor "normal, pre-warning and abnormal" market situations, or integrate the Alipay accounts of individual companies to create a consolidated public safe payment system based on careful study on the development trends of e-money and e-cash. This will also be elaborated in the following part of the paper.

\section{Change in Credit Conditions and Policies}

What is credit? What are the basic rules of credit activities? What is the credit condition? By clarifying this issue, this study have mastered the key to entering the market economy and seized the bull nose that promoted the construction of a modern economic system. 
Credit is a special and rare resource. It is special because, first, utilization brings more credit, on the contrary to average rare resources that get fewer; second, it is closely related to personality, political wisdom, friendship and affection; third, it is the basis of sound social development—without credit, social development would be expensive and plans are hard to implement due to high cost (or unpleasantness); fourth, credit exists freely and forms network, without compulsory obligations. Credit is intangible, unlike labor force or commodities that can be measured by time or quantity. It is communication based on mutual trust. You deposit your salary in a bank because you trust it. The banks earn credit and you get interest, which is a special award for your trust in the bank.

Credit activities have three basic rules: Law 1: Credit activities reflect both the real economy and the virtual economy. The real economy and the virtual economy are a balanced relationship. The real economy is the foundation, and the virtual economy is a reflection of the real economy financial form. Economic development requires financial deepening to promote the continuous improvement of productivity, and the real economy needs to achieve leap-forward development through the expansion of the virtual economy. Rule 2: Credit innovation has both positive and negative effects. Positive and negative effects are also a balanced relationship. It is the most important conditions for ensuring the healthy operation of the economy to correctly handle the relationship between the real economy and the virtual economy, correctly handle the relationship between financial innovation and financial supervision. Rule 3: Credit can be built, and credit construction can be promoted. From the deep analysis, this is because the law of value, the law of supply and demand, the law of competition and the law of balance will form a synergy in the development of market economy, forming an objective market check and balance mechanism to promote the survival of the fittest; this is due to the social appeal of credit activities. And moral appeals will form a social balance of progressive forces, produce an instinctive role, and promote credit construction. Of course, it is not enough to rely on the "invisible hand". It is also necessary for the superstructure to take the necessary measures and establish an effective mechanism to speed up the process. Credit activities can be developed and constructed. Just like the development and construction of material productivity, external factors (such as the coordination advantages of government organizations) combined with the fundamental role of the market can accelerate the construction of the market credit system [10].

Credit condition refers to the basis of mutual trust in trades. In this paper, it refers to the precondition for the conversion of credit into capital. It reflects not only the significance of integrity in credit trade, but also the special role of credit in creating new values. It is a fundamental condition for the modern economic and social development; it is also one of ten subjects of Social modernization [11]. As capital, credit causes great change in country's view of wealth, as wealth, it causes great change in country's economic strength, and as a strength, causes great change in country's comprehensive competitiveness.

The coverage of credit is far wider than financial assets. It includes, acts as and replaces money and financial assets. Credit creates values in wider and deeper levels. Credit value takes both tangible form such as means of production and living and virtual form such as brand, trademark and reputation. Credit value, in addition to value maintenance, trade, deposit and payment functions, also increases values such as real estate, copyright and patent. In the US, intangible assets such as marketing skill and reputation are increasingly important for giant banks' acquisition acts. About 70\% payments are made in form of credit [12].

Therefore, in the conversion of credit into capital, "reliability and standardization" are special conditions in addition to monetary and financial conditions.

The reliability reflects the possibility of credit to smoothly fulfill its functions in normal conditions. It has three essential factors: safety, quality, and compensation. Safety is the lifespan and the faultlessness when credit is used. Quality is required in the process of design and generation of credit. Compensation is the guarantee for credit. Therefore, the reliability based on safety, quality and compensation is essential for the generation and development of credit and for the conversion of credit into capital. For instance, land is potential credit but not necessarily capita. "Land can only be converted into capital through sales or mortgage under the condition of well-established property protection system and contract protection system"[13]. Furthermore, credit, either in the form of product or regulation, agreement or otherwise, should be reliable and trustworthy. Credit reliability reflects how much the virtual value of credit is converted into physical value, and how the society recognizes the value of credit. Credit reliability can be surveyed, analyzed and rated by such important indictors as credit development level. The three top appraisers: Standard \& Poor's, Moody and Fitch, from time to time issue credit rating reports that determine the wealth cost of countries, regions and companies.

The standardization shows the stability of credit value in the market, and shows the standard of credit instruments, credit products and credit forms in normal context. Despite of diverse credit instruments, credit products and credit forms, credit should be normalized and standardized in each process ranging from design and operation. Standardization helps in credit training and dissemination, enhance credit stability and fair value, establishes professional manager system, benefits agency business, and expands specialized credit businesses. Therefore, it is standards for credit development and conversion of credit into capital. In nature, modern economy is aggressive and calls for standard credit activities to expand production, improve techniques, update equipment and sell products. Domestic debt relationship or international economic partnership, they rely on standardized credit. Standardization is the foundation for modernization. As the economic globalization deepens, credit standardization will play an even important role in creating capital and wealth (see table 3). 
Table 3. Change in credit conditions and policies.

\begin{tabular}{ll}
\hline Precondition for the conversion of credit into Capital \\
\hline Credit Reliability & Quality, Safety, Compensation, Trustworthy \\
Credit Standardization & Stability, Standard, Fair value \\
\hline
\end{tabular}

With the development of modern economy, the value and characteristics of credit tend to be differentiated, diversified and complicated. This trend exacerbates the credit problem in modern economic society, which is a special problem that must be encountered in the transition from traditional economy to modern economy in the developing nations. So, in the new era, credit reliability and standardization are getting more and more important, while some negative factors increase. First, market uncertainty may impair credit reliability. Second, market asymmetry increases, for example, between virtual and real economies, between urban and rural finance, and asymmetric agency-larger gap between the interests of agents and clients. Third, market fluctuation gets tougher. In particular, the recent financial market both at home and abroad saw the largest abnormal fluctuation which imposes new pressures upon the reliability and standardization of credit. Fourth, conventional money is weakened. For example, the exchange and storage functions of conventional money are weakened. Young people prefer credit cards to cash. Fifth, the market culture is being readjusted. China is experiencing a revolution of consumption credit and Internet finance which is reforming the wealth management methods of families, especially young families. Sixth, there is a clear trend that financial capital is transforming into social capital, which sets new challenges for the traditional credit standardization.

In addition, China's credit conditions and policies have been significantly impacted by changes in international finance tendency [14]. For instance, new financial institution gains rapid development driven by new economy. The Asian Infrastructure Investment Bank (AIIB) and New Development Bank (NDB) become important supplements to modern international financial system. The developing countries hold more shares in the IMF equity structure of the World Bank. The international regulatory regulations are readjusted after the financial crisis. The important changes, on one hand, benefit the interaction between the two markets and improvement of China's credit system and policies, on the other, throw heavy pressure on China's credit conditions and market development.

China suffers severe credit defects. In the recent six decades, especially the three decades since the reform and opening-up, China presented remarkable achievements in modernization. The ancient country has shaken off its long backwardness and poverty and is exhibiting admirable development potential and the vigor of Chinese people. However, during the thirty-year market-oriented development, China also recorded extreme market economy with severe credit defects, including poor social integrity and credit, business fraud, negligence of contract and trustworthiness, counterfeiting, academic misconduct, tax fraudulence, etc., all of them are represented by poor public awareness of credibility and low credit level. The Chinese society is yet to promote values such as honesty and honoring one's words and contracts, repeatedly failing to prohibit false advertisement, illegal fundraising, commercial fraud, financial fraud, misleading publicity and fraudulent investment consulting.

Credit defects in China are especially reflected in the financing difficulty of small and micro businesses. By the end of 2017, there were around 28 million small and micro business entities and 62 million individually-owned businesses in China. Medium-, small-sized and micro businesses (including individually-owned ones) accounted for more than $90 \%$ of total market entities and contributed to over $80 \%$ employment, more than $70 \%$ patents of invention, over $60 \%$ GDP and more than $50 \%$ tax revenue nationwide. However, the loan coverage was only $17.3 \%$ among small and micro businesses. It took them four years and four months on average after their establishment to secure their first loan. Only approximately one third of them stayed in normal operation after three years since their incorporation and the average lifetime of small- and medium-sized enterprises was three years, in contrast to eight years of their counterparts in the United States and 12 years in Japan. In recent years, Chinese financial institutions' loan rate for small and micro businesses has maintained at about $6 \%$, the online lending rate $13 \%$, the registered rate of private lending in Wenzhou $15 \%$ and the rate of small-loan companies $15-20 \%$. [15]

The reasons are for credit deficiency in China: First, the traditional social structure and management system have created a fragile foundation for China's modern financial credit. China's traditional social structure, one is the authority that represents the authority of the state, and the other is a decentralized collection of individualized agricultural civilization. The flow of information between the two sides is mainly vertical flow from top to bottom. Credit transactions are mainly based on authoritative control. Second, the lack of sound regulations leads to high cost of trustworthiness and low cost of trustworthiness, which has caused the lack of internal motivation for the construction of China's modern market credit system. Third, China's excellent traditional culture, including religious practices, has not been carried forward well, resulting in the lack of necessary lubricants for the construction of China's modern market credit system. Fourth, the market values are improperly extended to politics, education, science, religion, culture and other social sectors, where individual profits are the exclusive goal. And the governments give priorities to investment attraction and project development rather than overall planning and balanced development. The importance is blindly attached to impractically high development speed and leap forward, while the development balance is neglected. Fifth, the influence factors of information disclosure quality based on industry difference [16]. Sixth, the poor deterrence of law, light punishment for violations, and the regulators' failure to detect and restrain in time inappropriate and excessive innovations and failure to disclose and punish in time false and fake innovations. It is the capital, technology and market rather than the institutions - the spirit of credit-centered market economy - that are introduced in. 


\section{Four Credit Development Campaigns}

In the era of Internet information economy, market environment changes are accelerating, credit contradictions are increasing and complicated, market irregularities and uncertainties are increasing, market risks are increasing, and market credit institutions, market credit supervision systems, and financial system infrastructure construction need to be further strengthened. In view of the new trends and market credit conditions, China may have to succeed in four campaigns to readjust and perfect policies, enhance credit development, take the initiatives and improve risk control.

\subsection{Campaign 1: On the Strategic and Ideological Level, It Is Urgent to Strengthen the Strategic Positioning of Credit Construction}

China may have to highlight the essential role of credit development. The core of financial business is to satisfy the society with products and services, and create market value and credit in the process of finding demands (business opportunities) and meeting demands. No matter how financial and market pattern changes or how up-to-date the financial products are, finance remains to be credit-centered. The market economy is a credit economy, and the construction of a market credit system is an endogenous power closely related to the economic development of traditional carriages and new carriages. It is necessary to stress that credit development is the foundation for market development, and stress that integrity is the guideline for conducts.

China may have to define the tasks and goals of deepened financial structure reform. In the following three decades and a longer period to run, China should set credit system development as the core of financial structure reform, in order to, based on laws, regulations, standards and contracts, build the credit record and credit infrastructures covering all social members, promote and foster the spirit of contract, create integrity culture, disseminate traditional credit morality, set up the credit incentive/punishment mechanism, and upgrade social integrity awareness and the level of credit. Regarding contracts, China need passion and capacity, motivation and pressure, and strong sense of contract. Respect to contracts is the epitome of rule of law. It is necessary to create a sound climate for the execution of contracts and disseminate strict code of conducts. The climate includes severe punishments that make violation of contracts unaffordable, social criticism that make violation unacceptable, frequent audit and inspection that make keep contract parties warned, feasible provisions that allow contract parties to perform, and definite contract value and importance that build up contract parties' sense of responsibility.

China may have to gain in-depth understanding of the importance of market credit system. Market credit system shows the development level, environment and condition of a country/region. Countries with developed market economy have sound market credit system. China, in the early stage of socialist market economy, is in urgent need of the support from market credit system. It is hard to achieve smooth economic transformation and development in a country with poor market credit. In the credit-centered modern economy, market credit system is the regulator that coordinates capital supply and demand, and is the essential foundation for harmonious social development.

China may have to stick to market-oriented finance, which is essential for China's financial theory, financial market concept and the development of finance [17]. First, China should reform the market structure and share. Along with interest rate liberation and market segmentation, the market will be divided by cost and risk. Driven by cost and profit, risk and return, the capital market will be divided by high, medium and low financing cost and risks. Large numbers of financial instruments and methods, such as bonds, guarantees, insurance, securities, intermediary services, will be created to apply to market segments and satisfy various customers. Second, China should reform the market concept and managerial rules to highlight high quality and high price, high risk and high return. Financial institutions will not simply prevent risks; they should make good use of risk as an important means of profit. Third, China should reform customers' understanding of financing and liability. Interest rate liberation observes the principle of credit rating-based pricing which will effectively improve customers' credit awareness, reform enterprises' ideas and practices that the more the liability, the higher the leverage, and set new and higher requirements on banks' level of credit rating and especially companies' level of financial analysis. Fourth, China should reform the way of market competition. Interbank competition will transform from simple competition in terms of loan procedures, loan condition and general services to overall competition in terms of interest rate-centered management level, business level, cost accounting, customer relationship and operating strategy. Fifth, China should reform customers' idea on financing risk management. Banks give different interest rates even for preferred industries, i.e. interest rate rises as loan increases. For enterprises, it means the cost of external finance varies: the more they rely on external finance, the higher the cost is. Exceeding the rational financing cost bar will bring heavy burden. The financing risk control philosophy is commonly accepted by banks and enterprises, which helps enterprises constrain blind financing impetus, improve self-constraint and rationality. Sixth, while continuing to expand financial openness, China will effectively strengthen market normative and reliable management and adhere to the interests of ordinary consumers.

\subsection{Campaign 2: At the Level of Financial Reform: There Is an Urgent Need to Improve the Design of Modern Financial Systems and Mechanisms}

China may have to create multi-dimensional and diverse financial ecology. The currently plain financial system hardly meets the demand for market diversification and segmentation and China will have to cope with the harsh competition in global market. China needs to build multi-dimensional financial structures to adapt to the open market. 
Multi-dimensional and diverse financial system, regarding the structured economic interests, calls for banking institutions at various levels and with various functions that meet the financial demands of customers from various levels [18] and involve the entire process of social and economic activities to swiftly detect potential market risks, especially in the early stages of risks. It is necessary that a large number of prosperous small and medium-sized banks form a multi-level banking system with strong market competitiveness and adapted to the structure of the primary, secondary and tertiary industries. In this sense, China needs to coordinate the relationship between "decentralization" and "centralization", and between "subtraction" and "addition". Chinese banking sector adopts the "centralization" strategy, resulting in over-centralization of human and financial resources in the Big Four. The numbers of outlets and employees of $\mathrm{ABC}$ are 50,000 and 500,000, ICBC 28,000 and 420,000, CCB 24,000 and 310,000, and BOC 13,000 and 200,000. Over-centralization impairs optimized allocation of social resources. Therefore, the strategy for regulatory system reform should be "decentralization" and then "re-centralization". Decentralization refers to that the state-owned giant banks appropriately break down some small and medium-sized banks targeted at local, regional or trans-regional customers, and attract social funds to set up more banks through market operation, so as to fully tap market competition. Decentralization can be made through subtraction or addition. The subtraction means banks are streamlined (cut down some institutions and lay off employees) for better corporate competitiveness. This may not be practical and the possible results may be heavier employment burdens of the society. The addition means to divide the banks into new banks and encourage private regional banks, in order to create new jobs.

The Big Four, though large in size, can hardly satisfy the financial needs of all market segments, regions and customers. The bureaucratism and the multi-level management organization system are the systematicroot that why the commercial banks are reluctant to loan to small-medium-sized enterprises. To make effective use of the RMB trillions financial resource of the country, China needs to extend the focus, through market competition or organizational division. In China's financial ecology, it is necessary to have six or seven internationally competitive banks, including policy and development financial institutions, and thousands of small and medium-sized banks. Only in this way could Chinese economy be guaranteed with strong financial support.

China may have to establish and perfect long-effective management mechanism. In the process of social and economic development, human perception is restricted despite of the developing technology. China could not fully understand the objective reality, nor can China fully control it. Regulators are part of the market and could not go beyond the market when identifying risks. Therefore, it is necessary to raise the awareness of risk prevention, establish and perfect the long-effective risk management mechanism. Risk compensation should be a key concern throughout the process of credit approval and management. In terms of organizational structures, credit policy formulation, execution and supervision should be separated to ensure the adequacy and effectiveness of constraint mechanism. Loan granting and post-lending management should be integrated to gradually optimize asset structure and elevate overall return of assets. Practical efforts should be made in fundamental works and priority given to the basic works of risk management, allowing the frontline to be informed of customer dynamics and make technical analysis of credit risks. China should actively explore credit innovation and credit portfolios, syndicate loan business, asset securitization and credit risk management tools. China should set up the mechanisms for examination, certification and continuous learning of credit risk managers to provide HR guarantee. Only through the long-effective banking credit risk management mechanism could China ensure the healthy and sustainable development of Chinese banking industry.

China may have to strengthen financial services. Finance as a medium changes along with the development of market economy. China made profits through increasing sales of products in 1950s, through increasing market shares by customer-centered integrated marketing in 1980s, and through increasing customer satisfaction by quality- and value-centered integrated corporate activities in 1990s. While in the contemporary times, profits should be gained through customers' lifelong value by value-centered integrated supply chain, which should give concerns to the following:

The first is the different service strategies for new and old customers, i.e. attracting new customers and maintaining old ones. New customers are attracted through increasing market share and expanding market scale, while old customers are maintained through better satisfaction, especially through good knowledge about competitors and timely improvement of services.

The second is the structure of financial service and marketing, including value communication, organizational core, delivered value and performance evaluation. The key points of organizational core are analysis of competition status, assessment of market environment, and decision on development scale and capability. As for value communication, it is to understand customers' value, demands, value flow and satisfaction. Those of delivered value are market segmentation, differentiated advantages, meeting customer needs and providing integrated supply and services. Those of performance evaluation are evaluation standards and the expressions of customers' value.

The third is the establishment of customer asset management system, which is an important element of financial service strategy, including determining the key characteristics of customer service quality, designing satisfactory and understandable customer reply language, and setting up a complete set of customer asset and resource models.

It is necessary for China's banking sector to make in-depth study on the marketing and service system, the financial service and marketing strategy, standards, methodology and 
performance evaluation rules adaptive to the current condition of China, "identify rural poverty causes and take targeted measures in turn"[19], define market segments and target markets, and the marketing strategy to fulfill market objectives.

\subsection{Campaign 3: At the Macro-Control Level: There Is an Urgent Need to Strengthen the Construction of Policy Transmission Mechanism}

The objective system of monetary policies includes ultimate objectives, intermediary objectives and operating objectives. The ultimate objectives, in addition to the common concerns over "economic growth, job opportunity and price stability", should include balanced development, which should also be the objectives of national macroeconomic policies. The intermediary objectives is that of the central bank to achieve the ultimate objectives, including for observable and re-adjustable indicators as well as disseminative financial variables such as interest rate, growth rate of money supply and total social financing. The central bank also sets up operating objectives, namely the short-term and direct objectives of monetary policies, such as base money and short-term interest rate. From the perspective of the law of balance, the above objectives are subject to three factors: maturity of the monetary policy dissemination mechanism, the acceptance of monetary policies by market players, and external pressure and level of gaming. Before the reform and opening-up, China's monetary policies were disseminated from $\mathrm{PBOC}$ to its branches and then to enterprises, i.e. simply and directly to the ultimate objectives. In the early stage of the reform and opening-up when the central bank system was established and financial institutions gained growth, the monetary policy dissemination system, from the central bank to financial institutions and then to enterprises, were initially set up, but the monetary market was not included. Since 1990s, the financial macro-control gradually transformed, the monetary market get developed, as a result, the dissemination was made from the central bank to the monetary market then to financial institutions and finally to enterprises, or from policies to operating objectives then to intermediary objectives and finally to the ultimate objectives. In recent years, the central bank made significant reform to the monetary policy control and dissemination system including, for example, the loan limit was cancelled to lay institutional foundation for the transformation of intermediary objectives to control over the amount of money supply, the deposit reserve system was reformed to make use of fund centralization and credit restructuring, the rediscount mechanism was reformed to link up rediscount interested rate with re-lending interest rate, operation of open market was expanded to highlight the initiative, flexibility, time-efficiency and justice of monetary policies, and interest rate including that of foreign currency was liberated to allow financial institutions to determine foreign currency loan interest rate based on the interest rate of the international market. Maintaining the stability of the renminbi is the need to safeguard the core interests of the country. Therefore, it is impossible for the central government to manipulate the value of RMB significantly. Currently some points about currency manipulation claims 'total rubbish', but China should be well prepared for the worst scenario if China-US trade tensions continue to worsen [20].

In general, the policy dissemination mechanism made some progress, but some critical weaknesses exist. First, the monetary market infrastructures need to be reinforced to bring more market players, solve market separation and push forward the bill market. Second, the interest rate has not yet access to the intermediary and operating objectives, and macro-control lacks flexible measures. Third, Chinese banks have not in-place modern bank operation mechanism and it is hard to increase the vertical and cross coverage of financial services. Fourth, the micro basis (enterprises and residents) of monetary policy dissemination should be improved. The above factors and practical conditions impair the effectiveness of China's macro-control policies. Along with the application of advanced technologies, such as Internet banking, the monetary circulation is accelerated, the efficiency of commodity trade improved, fund coverage expanded, and, however, the uncertainty and risk of financial activities are increased. Market players differ in appetite towards monetary policies, making it harder to implement the policies. External pressure and competition expose domestic problems to the world and make monetary policies more complicated. Chinese monetary policies are also subject to financial variables including exchange rate, interest rate, inflation and credit distribution policies. Against world economic restructuring and globalization, Chinese monetary policies are facing unprecedented tough challenges which call for proper economic philosophy and strategy to meet the demand of development and public expectation. At present, the monetary policies should "effectively deliver policy information, define policy orientation, so as to effectively guide market expectation and mitigate the pessimism" [21].

\subsection{Campaign 4: At the Policy and Technical Level: There Is Need to Improve and Enrich the Policy Toolbox}

In order to alleviate the impact of foreign exchange on liquidity, it's suggested to consider the policy mix of foreign exchange held by the people and foreign exchange settled by the state. A dynamic foreign exchange management mechanism should be established based on the foreign exchange reserve and the market status.

In order to lower the leverage ratio, the central bank may increase capital, promote debt-for-equity swap and increase capital with foreign exchange. Meanwhile, great efforts should be made to increase the capital output ratio, fund output ratio, labor productivity and total factor productivity.

In order to enrich choices of monetary instruments, besides traditional policy instruments such as the statutory reserve, discount rate of the central bank, fund rate of the central bank and open market operation, it's possible to consider seeking innovations in instruments including combination of investment, loans, debts and securities, and adopt money capital - bond policies at proper times. 
To prevent asset bubbles, money supply control alone is not enough. It's advised to regulate the stock and incremental capital through securitization, such as promoting stock asset-backed securitization to further revitalize the stock of assets of financial institutions. It's also advised to control the size by directionally regulating liquidity, such as directional lending, preferential policies and channel control.

In order to prevent and control Internet financial risks, it's workable to set up a unified online payment and settlement platform for non-banking institutions and improve legislation governing the behavior rules and policy standards of third-party payment and collection platforms. All online payments should be subject to regulation by unified standards to prevent market chaos.

In order to tighten grip over financial institutions that are "too big to fail", China may break them down as appropriate and spin specialized institutions and regional agencies off super institutions. Policy restrictions such as leverage control can be considered as well. Necessary restrictions should be imposed on the use of savings deposit - for example, it must not be used for proprietary trading. Risk rating for securities held by banks should be increased. There should be due firewalls between different markets. Though entirely separate operation is not realistic, intrinsic mechanisms should be in place to separate proprietary trading of various markets.

In order to better link the virtual economy and the real economy, innovation in master-feeder funds can be reinforced, national land funds set up and the supply system for food and necessities for labor protection established to meet the subsistence needs of disadvantaged groups.

In order to dissolve rural financial risks, a modern agricultural futures market can be established and a mechanism that can ensure safe, reliable and stable expectations for both supply and demand of farm produce can be set up to enhance farmers' resistance to price fluctuation risk, improve the efficiency of resource allocation and increase income.

In order to ease the difficulty in and unaffordability of financing for small and micro businesses, it's suggested to construct a financing service system covering the whole life cycle of these businesses. Assessment, incentives and policy support should be improved and financial institutions should be motivated to better serve small and micro businesses. More financing should be provided through regular financial channels to turn them into the main source of financing for small and micro businesses. Related policies and reform should focus on credit line less than RMB5 million for a single customer to improve the degree of precision of targeted RRR cuts for inclusive finance.

To give China more space to maneuver in the international futures market for iron ores and other bulk commodities, it's suggested to establish a nationwide unified coordination mechanism, study the operating mechanism and market status of the international futures market and properly combine fundamentals of futures to "increase the risk-carrying capacity of the economy as a whole"[22]. Meanwhile, China may consider forming an international bulk commodity purchase alliance with other demanders to negotiate with suppliers and realize mutual benefits for both supply and demand sides.

In order to prevent violent fluctuations in the stock market, the proportion of A-shares included into MSCI should be increased as much as possible while the inflow and outflow of funds are strictly monitored. Stable funds in the stock market should be established and related policies improved to protect interests of average individual investors.

In recent years, China's stock market has experienced significant fluctuations and declines, "due to a number of factors, "including the main national central bank interest rate increases, China's economic structure shattered, market expectations affect investor behavior, etc.[23] Chinese stock market is still in its infancy and the market trend is predominated by short-term market noises and reflexivity to which "they relate because false views lead to inappropriate actions"[24], rather than basic factors. As a result, the stock price soars sometimes and nosedives at others. It's because the market has too much speculation but too little investment, too many individual investors but too few investor clusters, too much passion but too little rationality, too many amateurs investors but few professional ones, and is eager to win but underdeveloped. Among individual investors, there are many students, small-business owners, unemployed urban citizens and those who illegally invest, but fortunately not so many farmers [25]. Speculation is spiked by domestic and foreign hot money, short-sighted institutional investors, and students and citizens longing for quick fortune. Chinese stock market mainly consists of individual investors who are compared to the sheep flock, while a mature market should be mainly composed of institutional investors. Ordinary individual investors enjoy unprecedented freedom in the Chinese stock market, which is inviting for them to gamble and lose rationality. Institutional investors are the minority, but they enjoy favorable positions and have absolute power in the stock market, prone to become the absolute winner. The basic conclusion is that in an immature market, speculation accounts for $70 \%$ and confidence $30 \%$. The stock market is in nature a game of gambling, players should be attentive, but there is no need to panic. Here is some advice: do not get swung by the public opinion and enhance ideological guidance and knowledge education when the market gives lessons to speculators; strictly control the flow of funds and unregulated financing, moderately slow down IPO, control the size of financing and securities lending and tightly control the frequency and size of position transfer; pay special attention to interval fluctuations of accumulation and liquidation, credit default swaps, the issuance of synthetic securities and systematic risks that might be presented by the size of concentrated securities position. Meanwhile, it's advised to enhance policy survey, testing and publicity, decide on the right time, method and intensity of system testing, appropriately prolong the unlock time of "non-tradable shares", handle stock index futures at the right time and slow the battles between bulls and bears, so as to slowly counterbalance different interests and demand and realize soft landing. 


\section{Conclusion}

In a word, along with technological, economic and social development, the content of value keeps expanding to cover, in addition to money and financial assets, such intangible values as innovation ability, brand quality, market rules and formulation of regulations which are the market basis for the in-depth economic globalization and international governance restructuring, the social basis for China's modernization and sustainable development, and the guarantee for ideology, product, management and development innovations. Therefore, credit, compared with money and financial products, is a higher-level social exchange medium that reflects wider social and economic cooperation.

Chinese economy has entered into the new normality. Slowed-down economic growth, restructuring and transformation are new and long-term trends instead of temporary abnormality. During the long-term transformation, some economic development conditions are changed (e.g. financial, monetary and credit conditions) and some remain unchanged (e.g. the essence of market economy based on credit development is not changed and becomes more important). In face of the changes and challenges, we should not only amend pertinent policies but also exhibit ideological determination. For example, in term of monetary policy, we should be prudent with such proposals as "critical turning", "policy restructuring" and "relax monetary policy via price". In China, steady appreciation of money builds up public confidence. It is critical for state stability and joining international community. Liquidity varies in different sectors in China, while in general is sufficient. The economic problems are not exclusively about nor can be solved solely through monetary policy. Should China have excess liquidity; it could not be absorbed by the international market, as the developed countries did. In this sense, it is steady monetary policies that are needed in China.

China is in a critical stage of deepening economic reform and fixing socialist market economy, a stage with strategic opportunities for accelerating transformation of development mode, a key stage of economic and social transformation, and a stage of upgrading its open economic level. Speeding up social credit system development is an important approach for the standardization of market economic order, improvement of market credit climate, lowering trade cost and preventing economic risks, an essential precondition for optimizing resource allocation, expanding domestic demands and promoting industrial structure upgrading, an effective measure for elevating social integrity, boosting social trustworthiness and minimizing social conflicts, an necessary precondition for building international brand and reputation, reducing foreign trade cost and upgrading China's soft strengths and international influence, and an urgent need for establishing an objective, just, reasonable and balanced international credit system to adapt to the new trend and pattern of globalization.

The Chinese financial market and current financial situation is large but not strong, malformed in structure, interested only in the virtual economy, not the real economy, circulating within its own system, and chaotic. The root cause lies in the absence of a sound market credit system. The excess capacity and stock are fundamentally the result of excessive production capital, which is caused by excessive financing leverage. The key to the success in reducing excess capacity, stock and leverage lies with de-leverage through "qualities to quantities' Meta-synthesis" [26]. Besides, over-capacity in China is the result of both corporate factors and impulse and macro imbalance of local government and reflects the structural adjustment of domestic and foreign market. To reduce excess capacity requires comprehensive measures that target root causes of over-capacity. On the basis of reducing excess capacity, stock, and leverage, China also need make great efforts to combat fake GDP. Cutting fake figures and building up internal strength might affect its ranking, but are more conducive to China's sustainability and can illustrate that China remains a developing country.

Financial system risks in addition to the factors China has already recognized, there are external evictions and impacts that China has uncontrollable. At present, some of the new trading models developed rapidly in China are supported by the Internet, and the invention and core technologies of the Internet are still mainly in developed countries. Whoever invents, who may know best how to destroy, this risk source must be highly valued.

The financial system and the environment will always interact and promote each other. The central bank should not only pay attention to its own balance sheet, but also the ability of the entire financial system to convert deposit reserve into financial institutions' disposable funds, and the ability of financial institutions to convert disposable funds into funds needed by the real economy. These two capabilities are directly related to the mobility of the whole society and have an important impact on meeting the needs of enterprises and individuals.

To sum up, while the international environment remains fundamentally the same and the domestic economy ushers in a new age of development, unbalanced, insufficient and uncoordinated development continues to trap the Chinese economy. China needs the balance mentality to figure out solutions. While opening up the financial sector wider, China should substantially tighten control over market regulation and reliability and firmly safeguard the interests of average consumers. China has many options of policy and technical instruments to prevent systematic financial risks, but the key lies in perfecting the modern credit system.

\section{References}

[1] William N. Goetzmann, K. Geert Rouwenhorst, The Origins of Value, translated by Wang yu, Wang Wongyu, China North Press, August 2010, p.4.

[2] Lixing Zou, China's Logic: the Balance Development, World Scientific, 2017, edition 1, pp.111-255.

[3] Chuanqi HE, Editor-in-Chief, China Modernization Report------Research on Industry Structure Modernization, Peking University Press, July 2018, pp.140-219. 
[4] Karl Marx, Capital, vol. 1, Part 2, the People's Publishing House, edition 1, June 1976, pp. 782-783.

[5] [US] Robert J. Shiller, the New Financial Order: Risk in the 21 st Century, CITIS Press, Jan. 2014, p. 237.

[6] [US] R. Glenn Hubbard, Anthony P O'Brien, Money, Banking and the Financial System, translated by Liu Qi, Lan Botao, Wang Yin, edition 2, Tsinghua University Press, December 2014, p. 4.

[7] Zou Lixing, Financial Empire: American Development and Enlightenment, Hunan University Press, May 2009, edition 1, p. 129.

[8] ZHANG Yao-long, LIU Dong: "On Rise and Cause of Sharing Economy", Journal of Dongbei University of Finance and Economics (Bi-Monthly), Number 2, 2018, General Serial No. 116.

[9] CHEN Liang: "A Review and Prospect for China's Balance Sheet Account", Journal of Dongbei University of Finance and Economics (Bi-Monthly), Number 2, 2018, General Serial No. 116.

[10] Zou Lixing, China's Rise: Development-Oriented Finance and Sustainable Development, World Scientific, 2015, edition 1, pp.70-75.

[11] [US] Martinelli A., Chuanqi HE: World Modernization Report: Paper Collection from the First World Modernization Forum, Scientific Press in China, October 2014, edition 1, p.20.

[12] Zou Lixing, Financial Empire: American Development and Enlightenment, Hunan University Press, May 2009, edition 1, pp. 219-220.

[13] Chen Zhiwu, Logic of Finance, China International Culture Press Limited, edition 1, June 2009, p. 21.

[14] XU Zhan-dong, WANG Xue-biao: "An Analysis on External Impacts, Money Multiplier Stability and Monetary Policy Roles", Journal of Dongbei University of Finance and Economics (Bi-Monthly), Number 3, 2017, General Serial No. 111.
[15] Data source: Speech by Yi Gang, governor of the People's Bank of China, at the 10th Lujiazui Forum on June 14, 2018.

[16] MA Lin, ZHOU Ji-yan: "Research on the Influence Factors of Information Disclosure Quality Based on Industry Difference: A Case Study on Listed Companies in Shenzhen during 2010-2013", Journal of Dongbei University of Finance and Economics (Bi-Monthly), Number 3, 2017, General Serial No. 111.

[17] Zou Lixing, China's Rise: Development-Oriented Finance and Sustainable Development, World Scientific, 2015, edition 1, pp.105-199.

[18] Zou Lixing, China's Base: County-Level Economy and Society, World Scientific, 2015, edition 1, pp.28-33.

[19] Xi Jingping, Xi Jingping's theory about Administering the State and the Government, China Foreign Languages Press, November 2017, p.83.

[20] Source: China Daily. com .cn/ business, Wednesday, October 17, 2018.

[21] Liu Yuanchun, "Restructuring China's Monetary Policy", Journal of Finance, vol. 10, 2015.

[22] [US] Stephen G. Cecchetti, Money Banking and Financial Markets, Beijing University Press, January 2006, p.203.

[23] Data source: Speech by Liu Ho, Vice Premier of the State Council of China, spoke with reporters from three central media in the morning of Friday, October 19, 2018.

[24] George Soros, THE LECTURES: At the Central European University, China CITIC Press, July 2013, pp108-109.

[25] Zou Lixing, "Research Rural Revitalization Strategy in China", Journal of Scientific Decision Making, vol.10, 19-34, 2017.

[26] Yu Jingyuan, "Development and Application of System Science and System Engineering", Journal of Scientific Decision Making, vol.12, 1-18, 2017. 